\title{
Supporting Information (SI): Molecular simulations of feldspar surfaces interacting with aqueous inorganic solutions: Interfacial water/ion structure and implications for ice nucleation
}

Anand Kumar*, Allan K. Bertram, Grenfell N. Patey*

Department of Chemistry, The University of British Columbia, Vancouver (V6T 1Z1), Canada (BC)

*Corresponding authors’ email: patey@chem.ubc.ca (G. N. Patey); anand@chem.ubc.ca (A. Kumar)

\section{S1. Description of the trajectory profiles presented as videos}

Table S1. Description of the trajectory profiles (as videos) presented in the SI. The videos show the top view and the side view of the lattice $\mathrm{K}^{+} / \mathrm{OH}$ exposed to water or solution, as well as solution ions and water molecules in the interfacial layer.

\begin{tabular}{ll}
\hline File Name & Description \\
\hline SemiRigid(001)_NH4Cl_300K.mp4 & Last $50 \mathrm{~ns}(1451-1500 \mathrm{~ns})$ for the semi-rigid (001) slab in \\
& $\mathrm{NH}_{4} \mathrm{Cl}$ solution at $300 \mathrm{~K}$ \\
SemiRigid(001)_LiCl_300K.mp4 & Last $50 \mathrm{~ns}(1451-1500 \mathrm{~ns})$ for the semi-rigid (001) slab in LiCl \\
& solution at $300 \mathrm{~K}$ \\
SemiRigid(001)_NH4Cl_230K.mp4 & Last $50 \mathrm{~ns}(2951-3000 \mathrm{~ns})$ for the semi-rigid (001) slab in \\
& $\mathrm{NH}_{4} \mathrm{Cl}$ solution at $230 \mathrm{~K}$ \\
Flexible(001)_NH4Cl_300K.mp4 & Last 50 ns $(1951-2000 \mathrm{~ns})$ for the fully flexible (001) slab in \\
& $\mathrm{NH} 4 \mathrm{Cl}$ solution at $300 \mathrm{~K}$
\end{tabular}

Legend for the species shown in the trajectory videos:

Red - Lattice $\mathrm{K}^{+}$; Purple - Lattice surface $\mathrm{OH}$; Light Green - $\mathrm{Li}^{+}$or $\mathrm{N}$ of $\mathrm{NH}_{4}^{+}$; Magenta $-\mathrm{H}$ of $\mathrm{NH}_{4}^{+}$; Brown $-\mathrm{Cl}^{-}$; Blue $-\mathrm{O}$ of water; Cyan $-\mathrm{H}$ of water 


\section{S2. Ion/Water model-specific response of microcline surfaces in contact with HCl solution}

As shown in Table 1, we simulated $\mathrm{HCl}$ solution using TIP4P/Ice and SPC/E water models. Note that $\mathrm{H}_{3} \mathrm{O}^{+}$was optimized for the SPC/E water model, and is not as well solvated with the TIP4P/Ice water model. The LJ parameters for $\mathrm{H}_{3} \mathrm{O}^{+}$were kept as optimized for the SPC/E model while the values for $\mathrm{Cl}^{-}$ were varied according to the water model used. The extent of adsorption of $\mathrm{H}_{3} \mathrm{O}^{+}$on the three surfaces was not affected by the choice of water model and/or interaction parameters of the ions (Figure 4). However, the (010) plane showed release of up to 18 and 4 lattice $\mathrm{K}^{+}$in cases where the interaction parameters for $\mathrm{H}_{3} \mathrm{O}^{+}$and $\mathrm{Cl}^{-}$were incompatible with the corresponding water model used i.e. TIP4P/Ice and SPC/E, respectively (Table 1). A comparison of the atomic density profiles for the (010) plane at the same concentration of $\mathrm{HCl}$ solution in SPC/E and TIP4P/Ice water models is shown in Figures S8 and $\mathrm{S} 10 . \mathrm{H}_{3} \mathrm{O}^{+}$is clearly not well solvated with TIP4P/Ice water molecules, hence, some are partly adsorbed on the surface with their protons primarily facing into the lattice and some migrate to the water/vapor (vacuum) interface. This is reflected in the different bulk concentrations of $\mathrm{H}_{3} \mathrm{O}^{+}$obtained for the different water models in contact with the (010) surface (Table 1). In contrast, the protons of adsorbed $\mathrm{H}_{3} \mathrm{O}^{+}$have no preferential orientation in the case of SPC/E water model. Therefore, the release of lattice $\mathrm{K}^{+}$in TIP4P/Ice case is likely due to the electrostatic repulsion between the protons of $\mathrm{H}_{3} \mathrm{O}^{+}$and $\mathrm{K}^{+}$. The (010) surface in contact with $\mathrm{HCl}$ solution is the only case where we noticed the release of $\mathrm{K}^{+}$being sensitive to the orientation of adsorbed $\mathrm{H}_{3} \mathrm{O}^{+}$with different water models. However, the $\mathrm{H}_{3} \mathrm{O}^{+}$model is not a good representation of excess protons near mineral surfaces, since the surface $\mathrm{OH}$ groups would typically get protonated in acidic conditions and affect the surface water orientation. 


\section{S3. Description of the simulation cell, interaction parameters for atoms and Z-cutoffs for evaluating ion exchange and adsorption}

Table S2. Comparison of simulation setup and results for various surfaces of K-feldspar exposed to pure water as reported by Soni and Patey (2019) and in this study.

\begin{tabular}{llll}
\hline Plane & Features & This Study & Soni and Patey (2019) \\
\hline \multirow{5}{*}{$(001)$} & Slab Thickness (in unit cell lengths) & 4 & 1 \\
& Lattice $\mathrm{K}^{+}$free to move & Yes & No \\
& H of surface OH free to move with fixed bond length of 0.1 nm & Yes & Yes \\
& Ice nucleation at 230 K & No & No \\
\hline \multirow{5}{*}{$(010)$} & Slab Thickness (in unit cell lengths) & 2 & 2 \\
& Lattice $\mathrm{K}^{+}$free to move & Yes & No \\
& H of surface OH free to move with fixed bond length of 0.1 nm & Yes & Yes \\
& Ice nucleation at 230 K & No & No \\
\hline \multirow{5}{*}{$(100)^{1}$} & Slab Thickness (in unit cell lengths) & 4 & 1 \\
& Lattice K+ free to move & Yes & No \\
& H of surface OH free to move with fixed bond length of $0.1 \mathrm{~nm}$ & Yes & Yes \\
& Ice nucleation at 230 K & No & No \\
\hline
\end{tabular}

${ }^{1}$ Soni and Patey (2019) investigated the following 3 variations of (100) plane (no ice nucleation reported in any case): (100)a (same as (100) in this study)

$(100) \mathrm{b}$ (closely resembles the ice-nucleating Al-surface of kaolinite in terms of surface proton structure)

(100)c similar to (100)a and has been investigated by Kiselev et al. (2017)

Table S3. The partial charges (in units of the elementary charge, e) on feldspar atoms and the corresponding Lennard-Jones parameters used in the simulations.

\begin{tabular}{ccccccll}
\hline \multirow{2}{*}{ Atom } & \multicolumn{4}{c}{ Charge } & \multicolumn{4}{c}{ Lennard-Jones } \\
\cline { 2 - 6 } & CLArameters & Remarks \\
\hline $\mathrm{Ni}$ & 2.1 & 2.02 & 2.0697 & 2.100079 & 0.3302 & $7.70065 \times 10^{-6}$ & Tetrahedral silicon \\
$\mathrm{Al}$ & 1.575 & 1.52 & 1.5631 & 1.57500249 & 0.3302 & $7.70065 \times 10^{-6}$ & Tetrahedral aluminum \\
$\mathrm{K}$ & 1 & 1 & 1 & 1 & 0.3334 & $4.1840 \times 10^{-1}$ & CLAYFF potassium \\
$\mathrm{O}$ & -1.05 & -1.094 & -1.0718907 & -1.0612809 & 0.31655 & $6.50194 \times 10^{-1}$ & Bridging oxygen \\
$\mathrm{Ot}$ & -1.1688 & -1.208 & -1.1911907 & -1.1762809 & 0.31655 & $6.50194 \times 10^{-1}$ & Bridging oxygen at \\
$\mathrm{Oh}$ & -0.95 & -0.99 & -0.96 & -0.99 & 0.31655 & $6.50194 \times 10^{-1}$ & Hydroxy oxygen \\
$\mathrm{Hh}$ & 0.425 & 0.41 & 0.42 & 0.425 & 0 & 0 & Hydroxy hydrogen \\
\hline
\end{tabular}


Table S4. Simulation cell details for various surfaces of feldspar (see Figure S2). Slabs for the (001) and (100) planes were four times a unit cell thickness, the (010) plane was two unit cells thick.

\begin{tabular}{|c|c|c|c|c|}
\hline \multirow{2}{*}{\multicolumn{2}{|c|}{ Axis }} & \multicolumn{3}{|c|}{ Dimensions (nm) } \\
\hline & & $(001)$ & $(010)$ & $(100)$ \\
\hline & $\mathrm{K}$ & 5.1 & 5.1 & 5.2 \\
\hline & Y & 5.2 & 4.6 & 4.3 \\
\hline \multirow{4}{*}{ Z } & $\mathrm{a}$ & 4.5 & 2.4 & 3.8 \\
\hline & $\mathrm{b}$ & 4.9 & 4.7 & 5.5 \\
\hline & $\mathrm{c}$ & 2.6 & 1.4 & 3.4 \\
\hline & $\mathrm{d}$ & 9.5 & 1.1 & 9.3 \\
\hline
\end{tabular}

Table S5. Z-cutoffs used for counting adsorbed ions on the semi-rigid surfaces of feldspar exposed to various solutions at $300 \mathrm{~K}$.

\begin{tabular}{|c|c|c|c|c|c|c|}
\hline \multirow{3}{*}{ Solute } & \multicolumn{6}{|c|}{ Z-cutoffs for evaluating adsorbed ions (nm) } \\
\hline & \multicolumn{2}{|c|}{ (001) } & \multicolumn{2}{|c|}{$(010)$} & \multicolumn{2}{|c|}{ (100) } \\
\hline & Cation & Anion & Cation & Anion & Cation & Anion \\
\hline $\mathrm{NH}_{4} \mathrm{Cl}$ & 12.25 & 12.68 & 2.50 & 2.84 & 12.75 & 13.05 \\
\hline $\mathrm{HCl}$ & 12.35 & 12.70 & 2.50 & 2.84 & 12.75 & 13.10 \\
\hline $\mathrm{LiCl}$ & 12.25 & 12.60 & 2.50 & 2.84 & 12.75 & 13.00 \\
\hline $\mathrm{CsCl}$ & 12.38 & 12.75 & 2.50 & 2.84 & 12.75 & 13.05 \\
\hline $\mathrm{KCl}$ & 12.30 & 12.60 & 2.50 & 2.84 & 12.75 & 13.10 \\
\hline
\end{tabular}

Table S6. Z-cutoffs used for counting exchanged and adsorbed cations on the fully flexible surfaces of feldspar exposed to various solutions at $300 \mathrm{~K}$.

\begin{tabular}{ccccccc}
\hline \multirow{2}{*}{ Solute } & \multicolumn{5}{c}{ Z-cutoffs for evaluating exchanged/adsorbed cations $(\mathrm{nm})$} \\
\cline { 2 - 7 } & \multicolumn{2}{c}{$(001)$} & \multicolumn{3}{c}{$(010)$} & \multicolumn{2}{c}{$(100)$} \\
\cline { 2 - 7 } & Added Cation & Released K & Added Cation & Released K & Added Cation & Released K \\
\hline $\mathrm{NH}_{4} \mathrm{Cl}$ & $11.95 / 12.20$ & $11.95 / 12.20$ & $2.50 / 2.50$ & $2.50 / 2.50$ & $12.50 / 12.75$ & $12.75 / 12.86$ \\
$\mathrm{HCl}$ & $12.12 / 12.30$ & $12.05 / 12.35$ & - & - & - & - \\
$\mathrm{LiCl}$ & $12.05 / 12.25$ & $12.05 / 12.25$ & - & - & - & - \\
$\mathrm{KCl}$ & $12 / 05 / 12.30$ & $12.05 / 12.25$ & - & - & - & - \\
\hline
\end{tabular}





Figure S1. Top and side views of the three surfaces of K-feldspar used in the simulations. Slabs for the (001) and (100) planes were four times a unit cell thickness, (010) plane was two unit cells thick. 


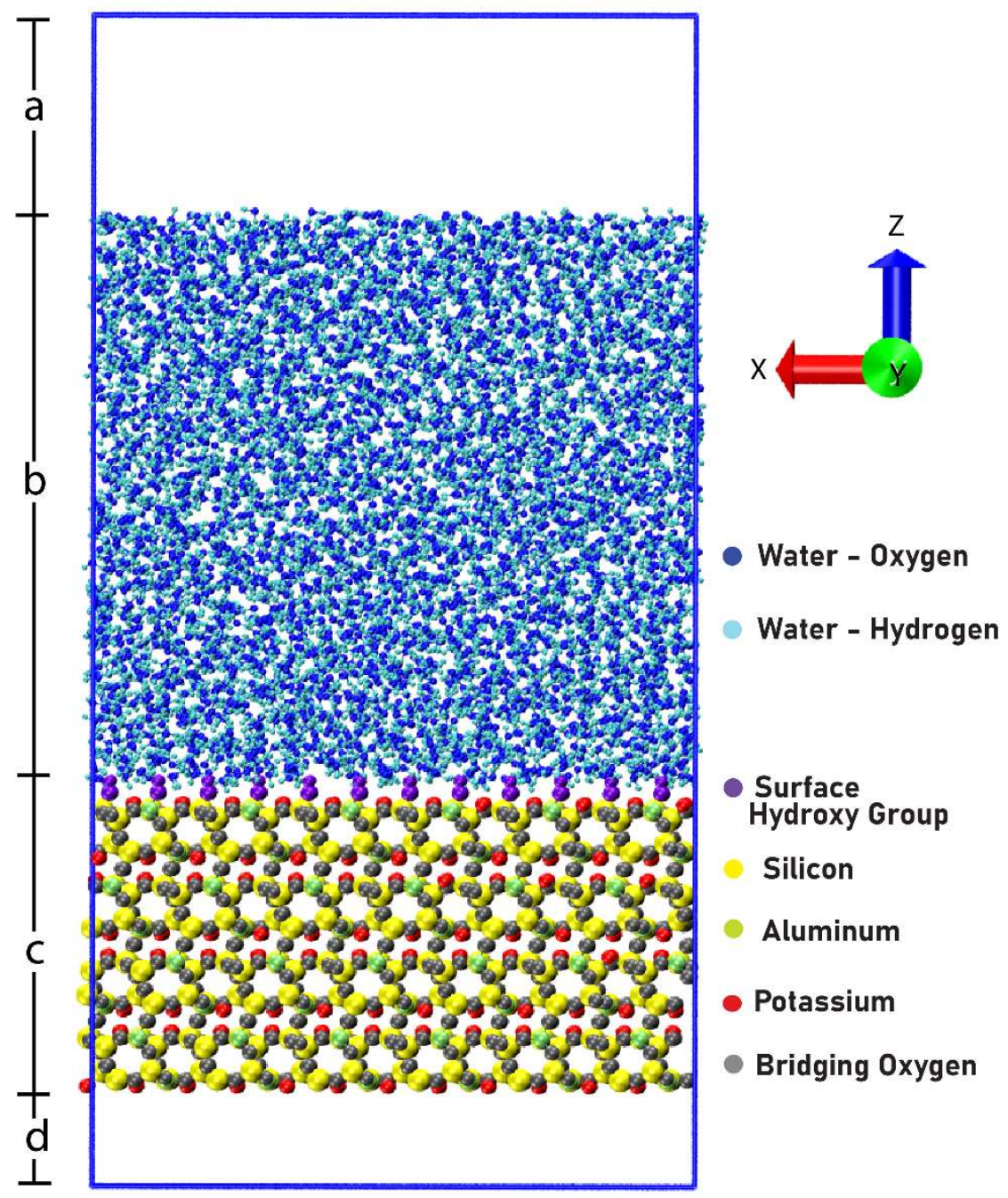

Figure S2. Illustration of the initial configuration of a typical simulation box with NPT conditions. The snapshot shows the (001) surface exposed to TIP4P/Ice water molecules. The box dimensions for various slabs of K-feldspar are given in Table S3. 
S4. Atomic density profiles and snapshots of (001), (010) and (100) surfaces in various solutions at $300 \mathrm{~K}$
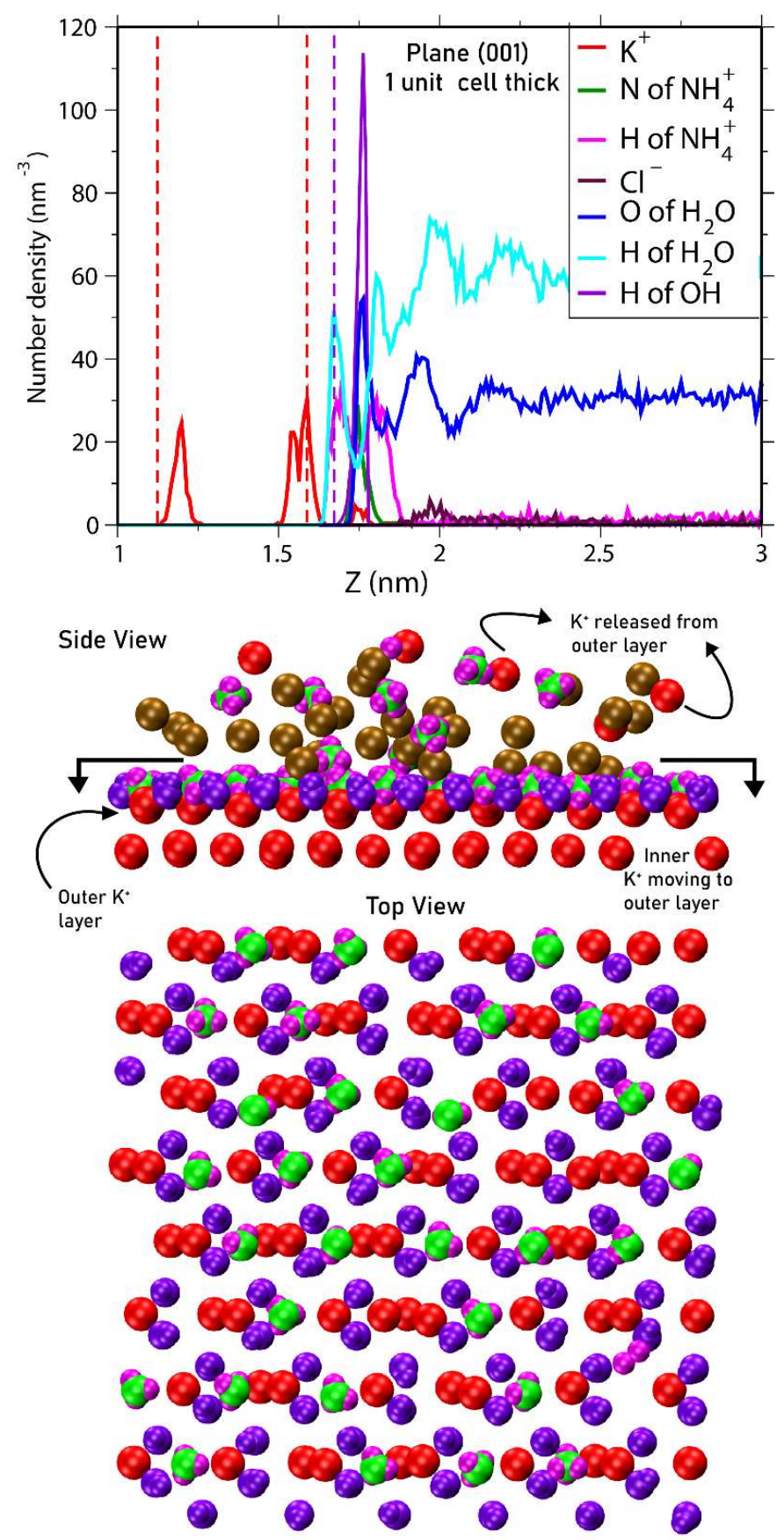

Figure S3. Atomic density profiles (upper panel), side view (middle panel) and top view (bottom panel) for the semi-rigid (001) surface of $\mathrm{K}$-feldspar (microcline phase) in $\mathrm{NH}_{4} \mathrm{Cl}$ solution $\left(96 \mathrm{NH}_{4}^{+}, 96 \mathrm{Cl}^{-}\right.$) after equilibrating for $700 \mathrm{~ns}$ at $300 \mathrm{~K}$. Note that this (001) plane is only one unit cell thick. The Zaxis in the density profile represents the direction orthogonal to the surface. The Z-range (or cross sectional height) in the side view is kept the same as in the density profile, while the top view only shows the surface layer (depicted by the black arrows). For clarity, water molecules and bulk lattice are not shown in the snapshots. The color coding for the atoms in the snapshots is consistent with the density profile. Dashed red and violet lines in density profile indicate the initial positions of the lattice $\mathrm{K}^{+}$layers and Os of surface $\mathrm{OH}$ groups, respectively. 


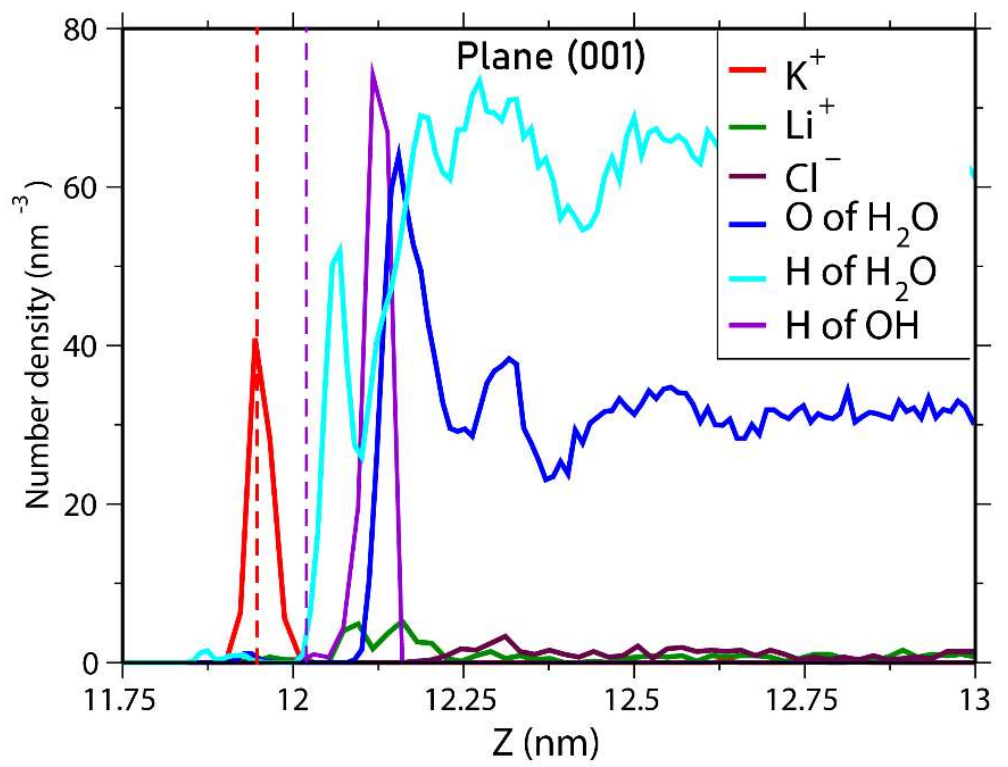

Top View

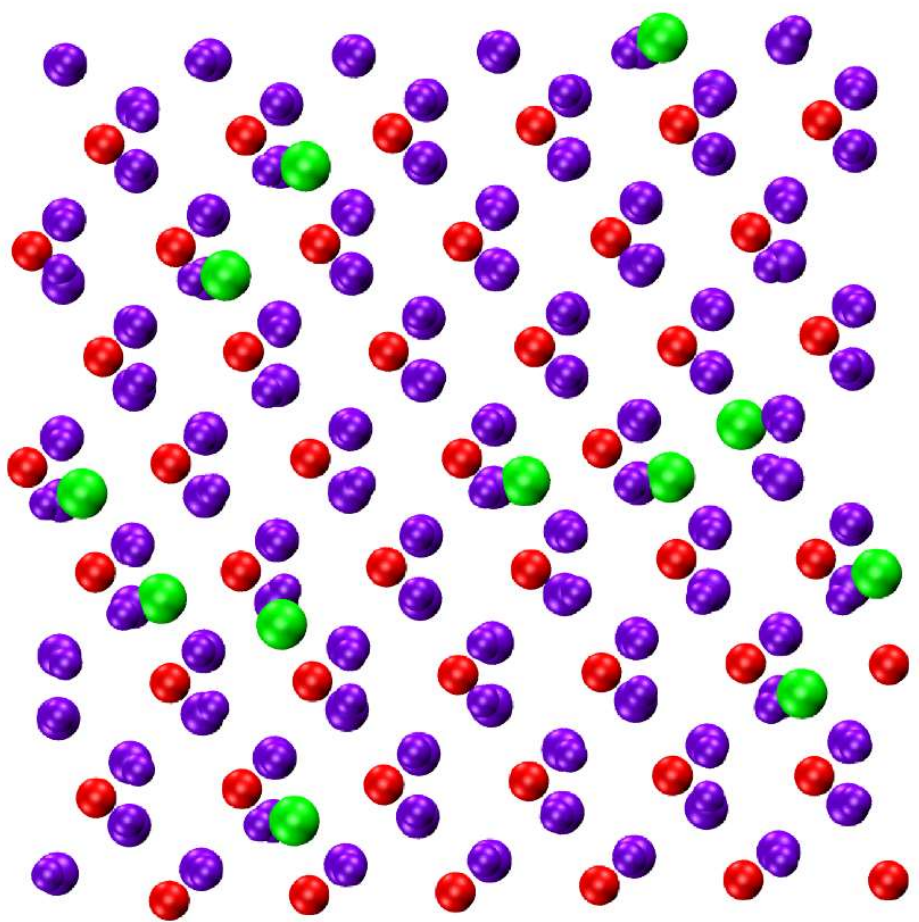

Figure S4. Atomic density profiles (upper panel) and top view (bottom panel) for the semi-rigid (001) surface of $\mathrm{K}$-feldspar in $\mathrm{LiCl}$ solution $\left(96 \mathrm{Li}^{+}, 96 \mathrm{Cl}^{-}\right)$after equilibrating for $1500 \mathrm{~ns}$ at $300 \mathrm{~K}$. The Zaxis in the density profile represents the direction orthogonal to the surface. The top view shows the surface layer (up to $Z=12.25 \mathrm{~nm}$ ). For clarity, water molecules and bulk lattice are not shown in the snapshots. The color coding for the atoms in the snapshots is consistent with the density profile. Dashed red and violet lines in upper panel indicate the initial positions of outermost lattice $\mathrm{K}^{+}$layer and Os of surface $\mathrm{OH}$ groups, respectively. 


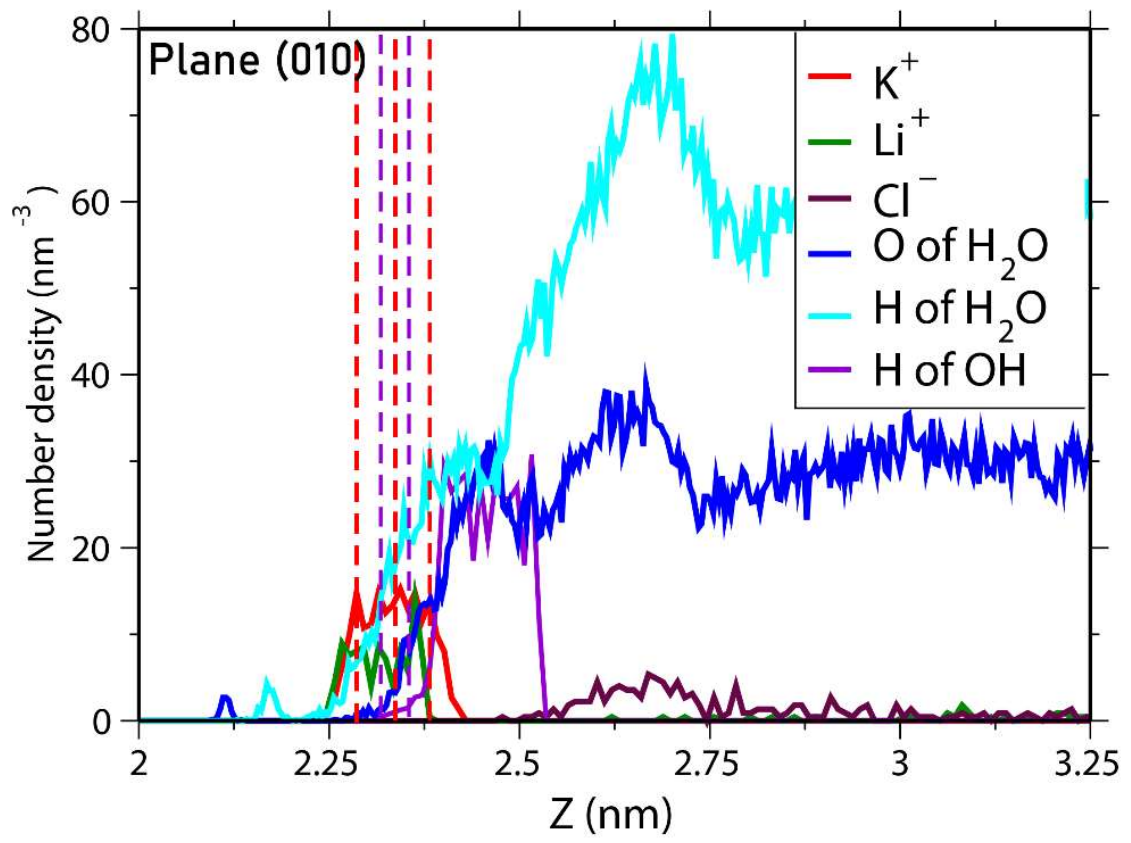

Top View
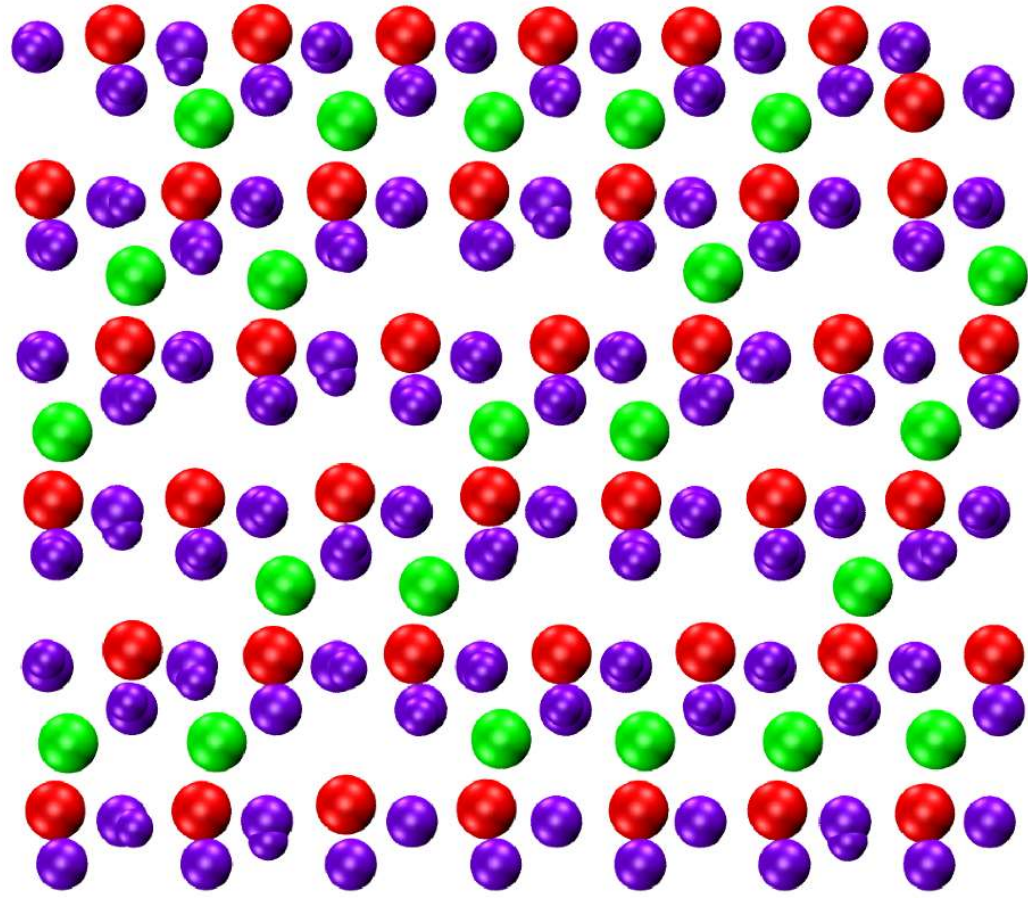

Figure S5. Same as Figure S4, for the semi-rigid (010) surface of K-feldspar in $\mathrm{LiCl}$ solution $\left(84 \mathrm{Li}^{+}\right.$, $84 \mathrm{Cl}^{-}$) after equilibrating for $1500 \mathrm{~ns}$ at $300 \mathrm{~K}$. The top view shows the surface layer (up to $\mathrm{Z}=2.5$ $\mathrm{nm})$. 


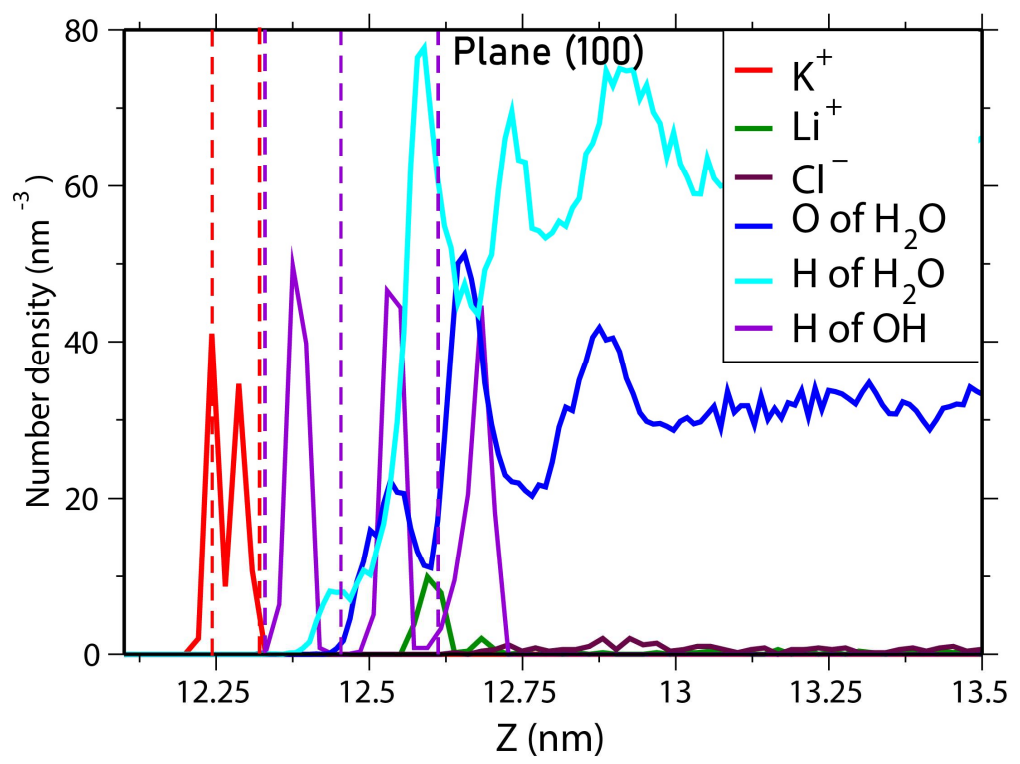

Top View

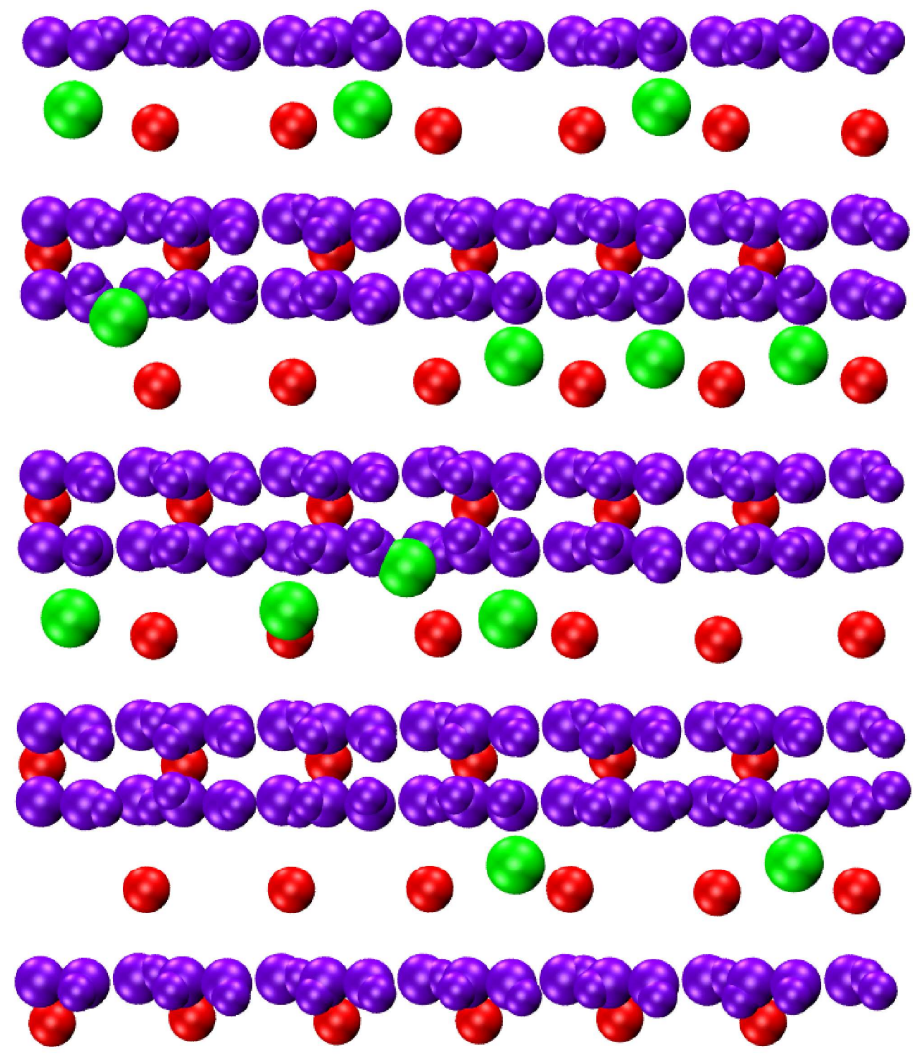

Figure S6. Same as Figure S4, for the semi-rigid (100) surface of K-feldspar in LiCl solution (48 $\mathrm{Li}^{+}$, $48 \mathrm{Cl}^{-}$) after equilibrating for $1500 \mathrm{~ns}$ at $300 \mathrm{~K}$. The top view shows the surface layer (up to $\mathrm{Z}=12.75$ $\mathrm{nm})$. 

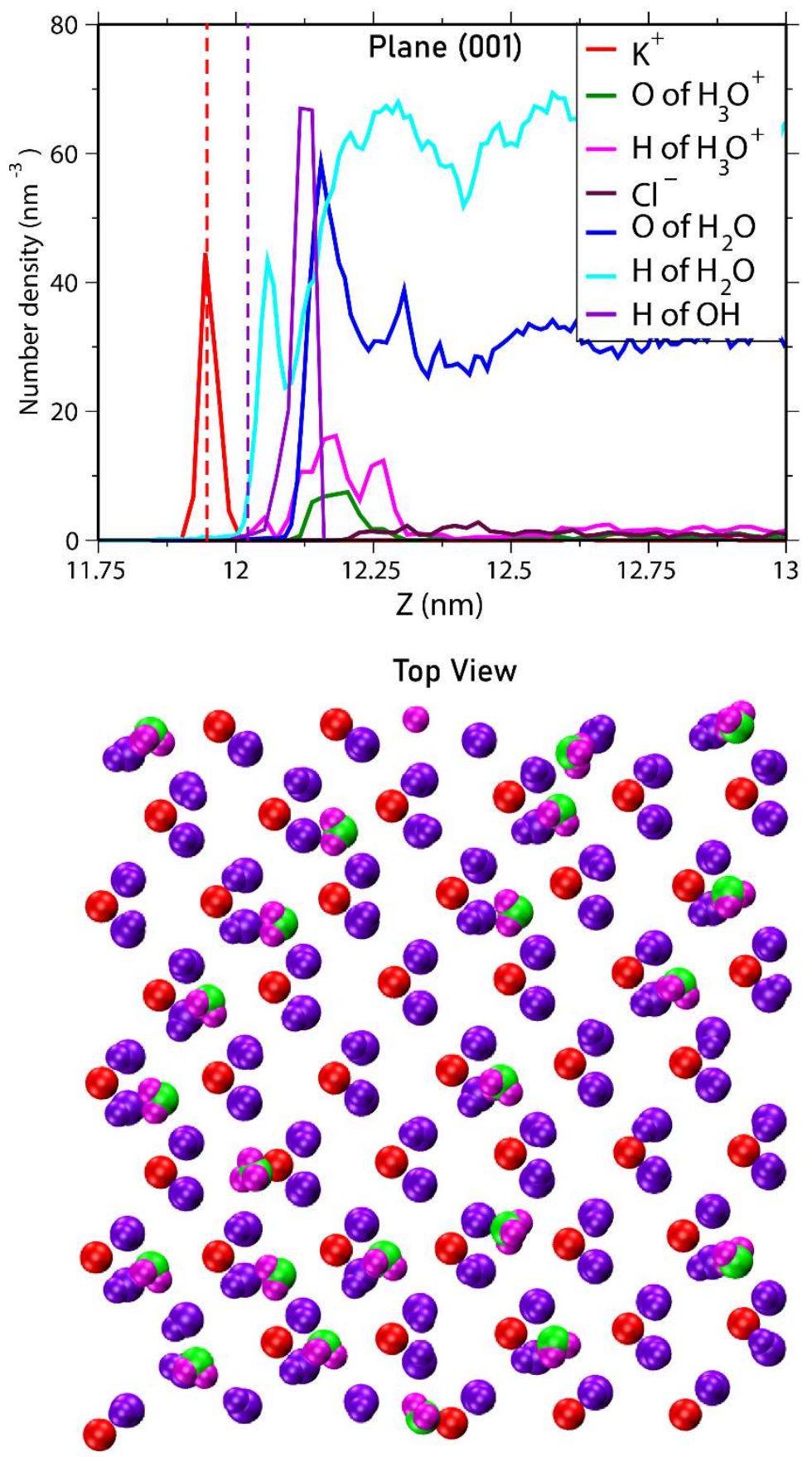

Figure S7. Atomic density profiles (upper panel) and top view (bottom panel) for the semi-rigid (001) surface of $\mathrm{K}$-feldspar in $\mathrm{HCl}$ solution $\left(96 \mathrm{H}_{3} \mathrm{O}^{+}, 96 \mathrm{Cl}\right)$ after equilibrating for $1500 \mathrm{~ns}$ at $300 \mathrm{~K}$. The SPC/E water model was used. The interaction parameters for $\mathrm{H}_{3} \mathrm{O}^{+}$and $\mathrm{Cl}$ used here are optimized for SPC/E water model. The Z-axis in the density profile represents the direction orthogonal to the surface. The top view shows the surface layer (up to $Z=12.25 \mathrm{~nm}$ ). For clarity, water molecules and bulk lattice are not shown in the snapshots. The color coding for the atoms in the snapshots is consistent with the density profile. Dashed red and violet lines in density profile indicate the initial positions of the outermost $\mathrm{K}^{+}$layers and Os of surface $\mathrm{OH}$ groups, respectively. 

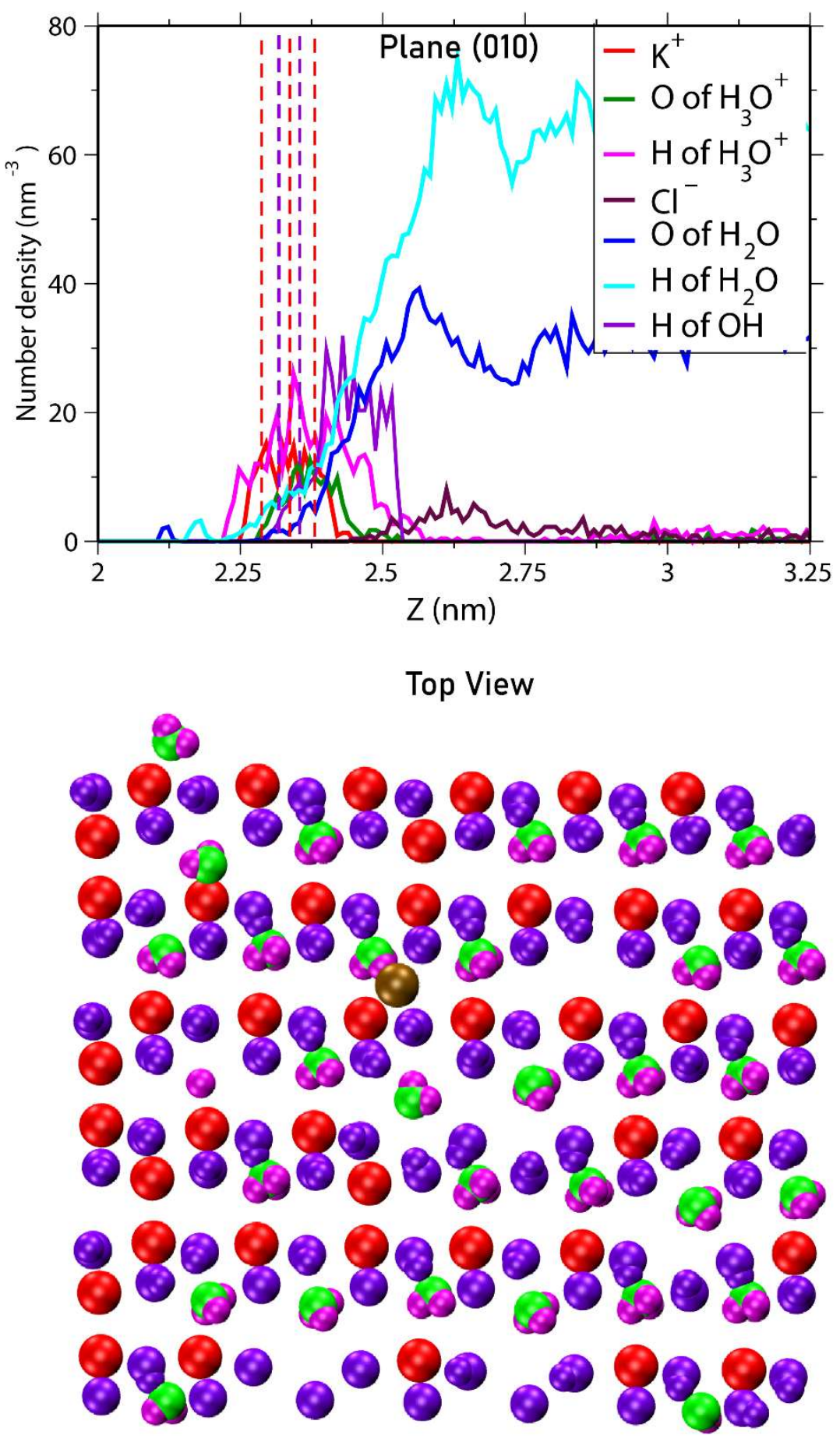

Figure S8. Same as Figure S7, for the semi-rigid (010) surface of K-feldspar in $\mathrm{HCl}$ solution $\left(84 \mathrm{H}_{3} \mathrm{O}^{+}\right.$, $84 \mathrm{Cl}^{-}$) after equilibrating for $1500 \mathrm{~ns}$ at $300 \mathrm{~K}$. The SPC/E water model was used. The interaction parameters for $\mathrm{H}_{3} \mathrm{O}^{+}$and $\mathrm{Cl}^{-}$used here are optimized for the SPC/E water model. The Z-axis in the density profile represents the direction orthogonal to the surface. The top view shows the surface layer (up to $Z=2.5 \mathrm{~nm}$ ). 


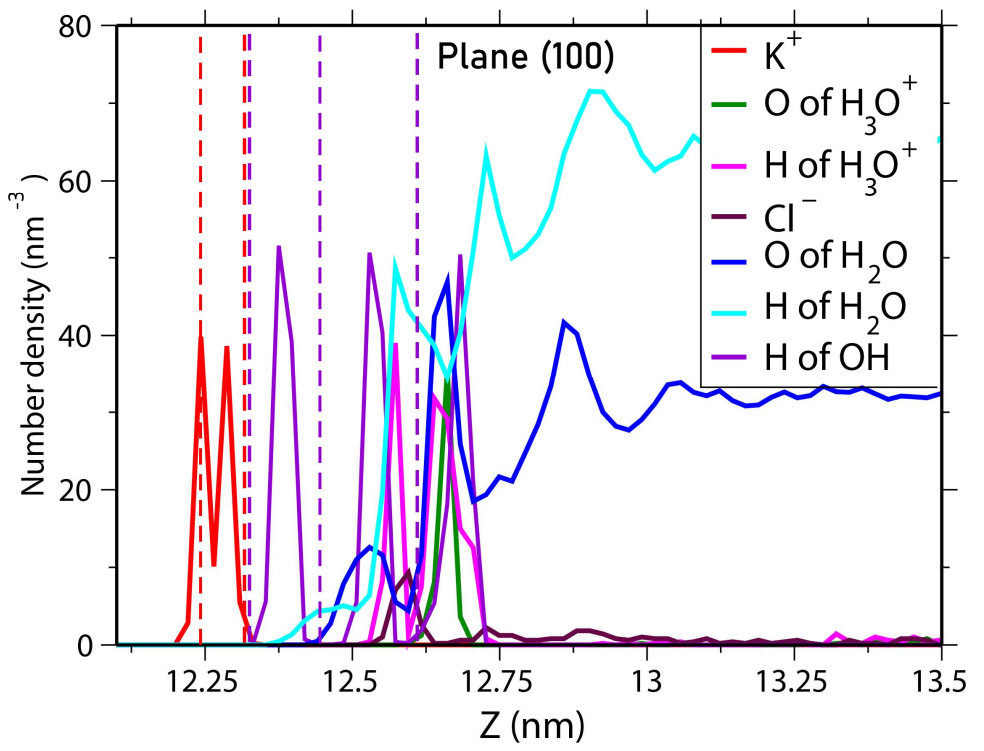

Top View

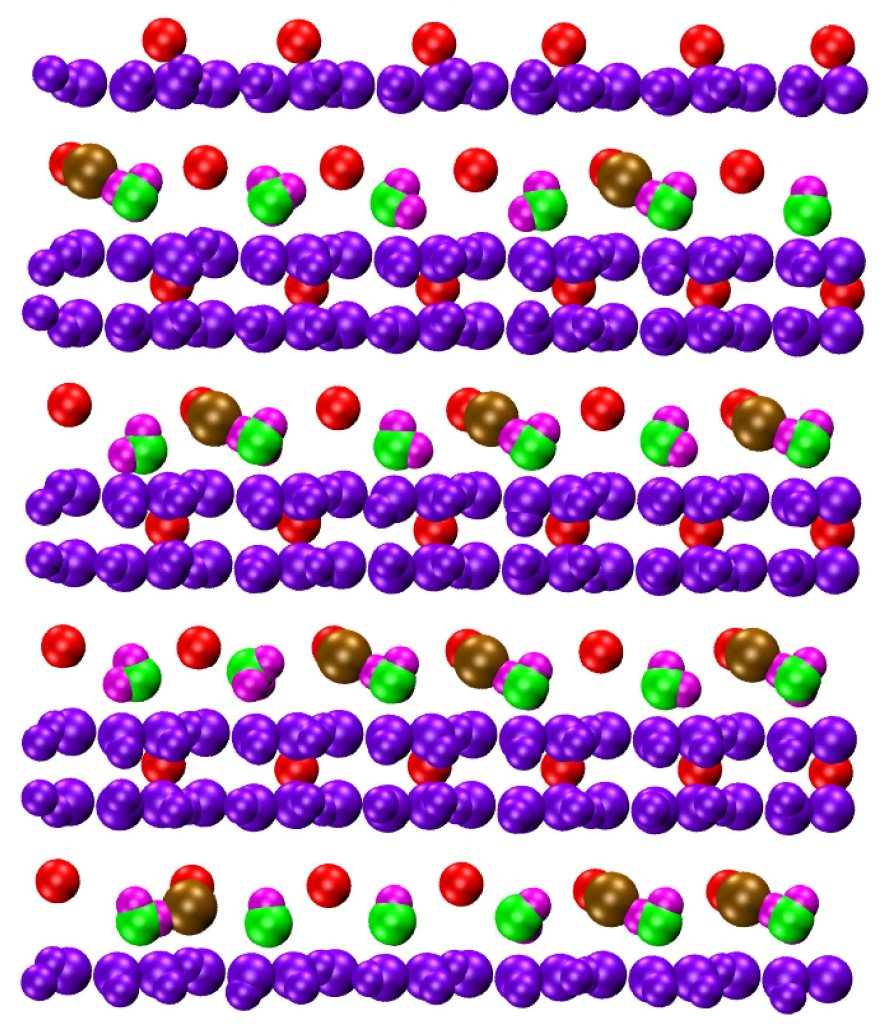

Figure S9. Same as Figure S7, for the semi-rigid (100) surface of K-feldspar in $\mathrm{HCl}$ solution $\left(48 \mathrm{H}_{3} \mathrm{O}^{+}\right.$, $48 \mathrm{Cl}^{-}$) after equilibrating for $1500 \mathrm{~ns}$ at $300 \mathrm{~K}$. The SPC/E water model was used. The interaction parameters for $\mathrm{H}_{3} \mathrm{O}^{+}$and $\mathrm{Cl}^{-}$used here are optimized for the SPC/E water model. The Z-axis in the density profile represents the direction orthogonal to the surface. The top view shows the surface layer (up to $Z=12.75 \mathrm{~nm}$ ). 


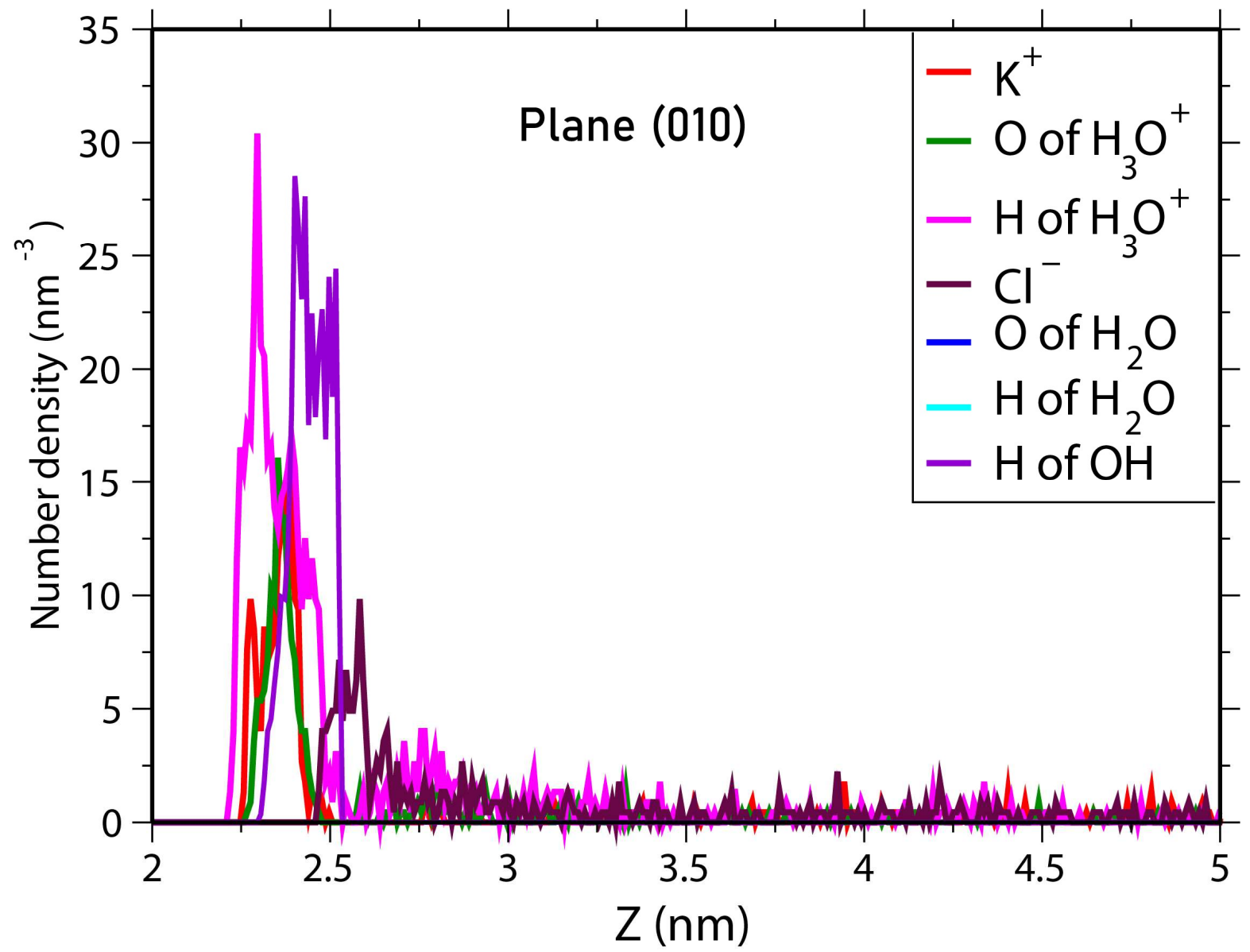

Figure S10. Atomic density profiles for the semi-rigid (001) surface of K-feldspar in $\mathrm{HCl}$ solution ( 96 $\mathrm{H}_{3} \mathrm{O}^{+}, 96 \mathrm{Cl}^{-}$) after equilibrating for $1500 \mathrm{~ns}$ at $300 \mathrm{~K}$. The TIP4P/Ice water model was used. The interaction parameters for $\mathrm{H}_{3} \mathrm{O}^{+}$and $\mathrm{Cl}^{-}$used here are optimized for the SPC/E and TIP4P/Ice water model, respectively. The Z-axis in the density profile represents the direction orthogonal to the surface. 

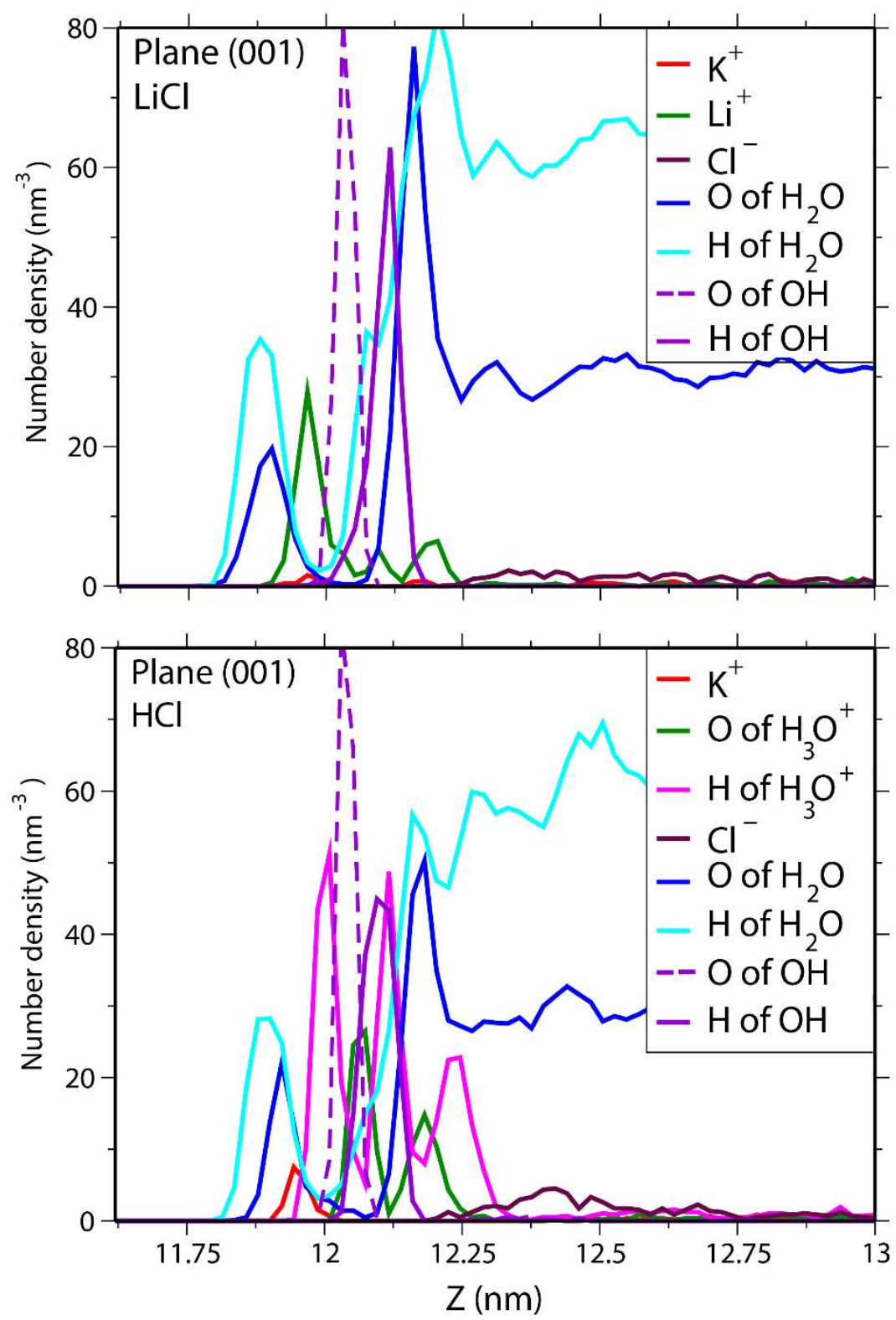

Figure S11. Atomic density profiles for the fully flexible (001) surface of K-feldspar in LiCl (upper panel; $96 \mathrm{Li}^{+}, 96 \mathrm{Cl}^{-}$) and $\mathrm{HCl}$ solution (lower panel; $96 \mathrm{H}_{3} \mathrm{O}^{+}, 96 \mathrm{Cl}^{-}$) after equilibrating for $2000 \mathrm{~ns}$ at $300 \mathrm{~K}$. For $\mathrm{LiCl}$ case, the TIP4P/Ice water model was used with corresponding parameters for $\mathrm{Li}^{+}$ and $\mathrm{Cl}^{-}$. For $\mathrm{HCl}, \mathrm{SPC} / \mathrm{E}$ water model is used and the interaction parameters for $\mathrm{H}_{3} \mathrm{O}^{+}$and $\mathrm{Cl}^{-}$used here are optimized for the SPC/E and TIP4P/Ice water model, respectively. The Z-axis in the density profile represents the direction orthogonal to the surface. 


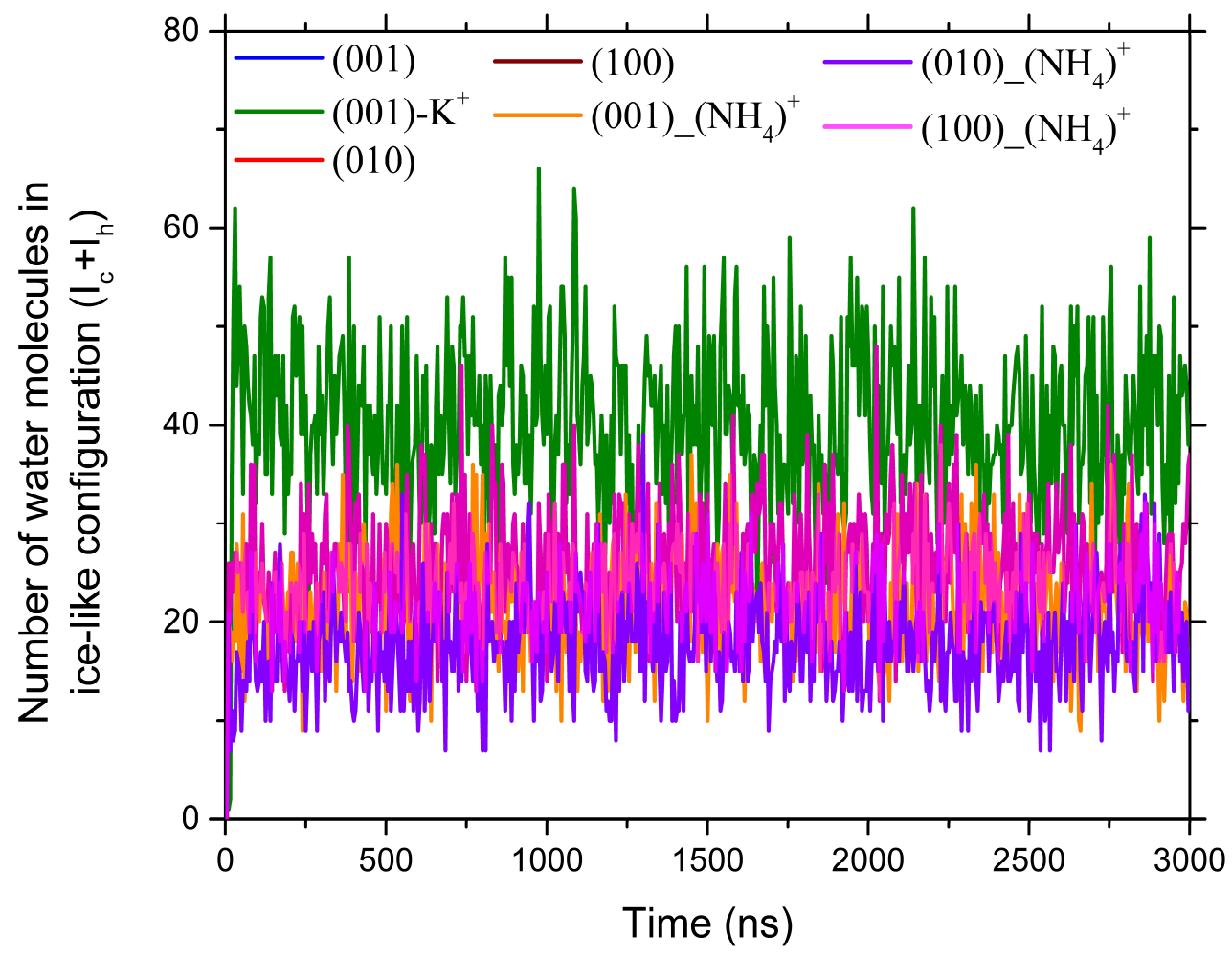

Figure S12. CHILL algorithm plots for the total number of water molecules in ice-like configurations in various systems as functions of simulation time. Results include semi-rigid thick slabs of (001), (010), (100) and completely rigid non-stoichiometric (001)- $\mathrm{K}^{+}$in TIP4P/Ice water at $230 \mathrm{~K}$ for 3000 ns. The initial configurations for these runs are taken from the end of $300 \mathrm{~K}$ runs of the planes in water after being equilibrated for $200 \mathrm{~ns}$. In addition, we show results of semi-rigid (001), (010) and (100) slabs in $\mathrm{NH}_{4} \mathrm{Cl}$ solution (96, 84 and 48 ammonium ions, respectively) at $230 \mathrm{~K}$ for $3000 \mathrm{~ns}$. The initial configurations for these runs are taken from the end of $300 \mathrm{~K}$ runs of the planes in the same solution after being equilibrated for $1500 \mathrm{~ns}$ (i.e. after the cation adsorption had reached saturation). Ice nucleation is not observed in any system. 


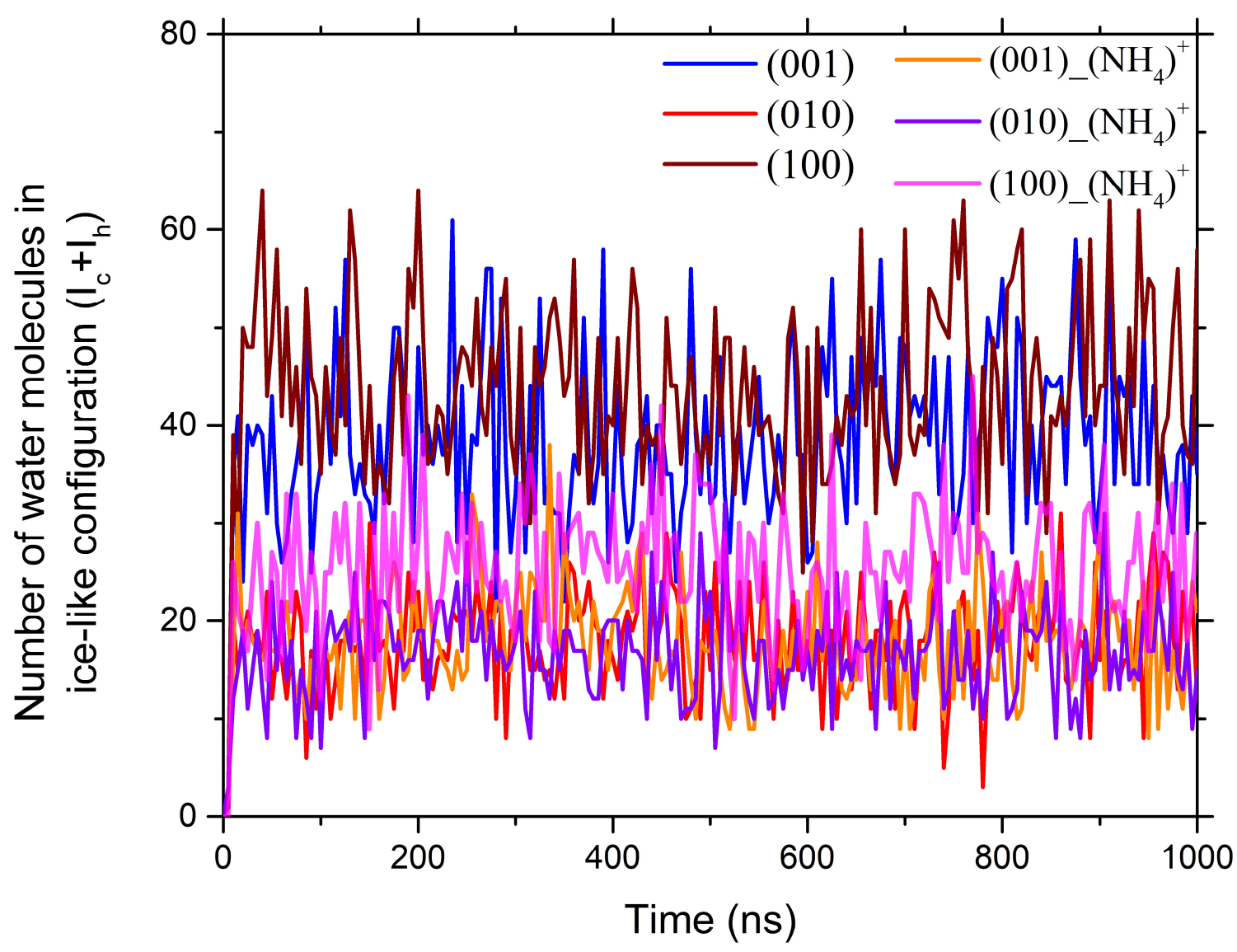

Figure S13. CHILL algorithm plots for the total number of water molecules in ice-like configurations in various fully flexible systems as functions of simulation time. Results include fully flexible thick slabs of (001), (010) and (100) in TIP4P/Ice water at $230 \mathrm{~K}$ for $1000 \mathrm{~ns}$. The initial configurations for these runs are taken from the end of $300 \mathrm{~K}$ runs of the fully flexible slabs in water after being equilibrated for $200 \mathrm{~ns}$, then converted to semi-rigid systems and quenched to $230 \mathrm{~K}$. In addition, we show results of fully flexible (001), (010) and (100) slabs in $\mathrm{NH}_{4} \mathrm{Cl}$ solution $(96,84$ and 48 ammonium ions, respectively) at $230 \mathrm{~K}$ for $1000 \mathrm{~ns}$. The initial configurations for these runs are taken from the end of $300 \mathrm{~K}$ runs of the fully flexible slabs in the same solution after being equilibrated for $2000 \mathrm{~ns}$, then converted to semi-rigid system and quenched to $230 \mathrm{~K}$. Ice nucleation is not observed in any system. 